\title{
Metodologias Alternativas no Ensino de Ciências: Uso de teatro e mitologia no ensino de movimentos internos da Terra
}

Alternative Methodologies in Teaching Sciences: Use of theater and mythology in the teaching of internal movements of the Earth

Metodologías Alternativas en Ciencias de la Enseñanza: Uso del teatro y mitología en la enseñanza de movimientos internos de la Tierra

Gabrielly Carvalho Andrade

Licencianda em Biologia, UFLA, Brasil e-mail gabihandrade14@gmail.com

Bianca Morais de Souza Licenciando em Biologia, UFLA, Brasil e-mail biancamsouza96@gmail.com

Laise Vieira Gonçalves Professora Mestre, UFLA, Brasil laisebiologa@gmail.com

Antonio Fernandes Nascimento Junior

Professor Doutor, UFLA, Brasil toni_nascimento@yahoo.com.br 


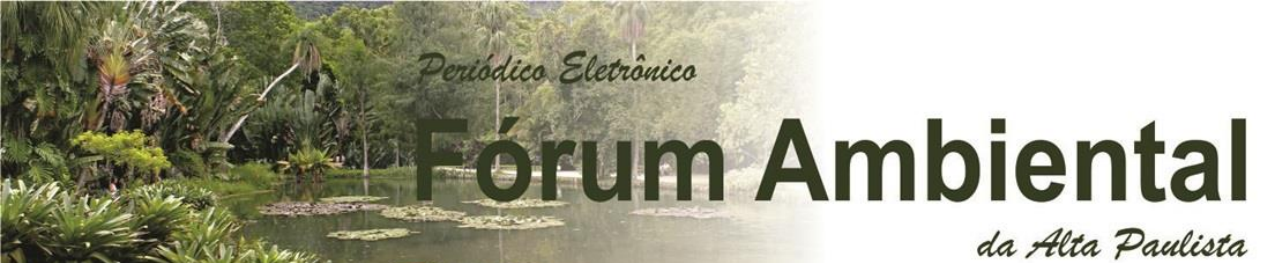

Volume 14, Número 5, 2018

ISSN 1980-0827

da Alta Paulista

\section{RESUMO}

Objetiva-se com este trabalho relatar e analisar uma aula desenvolvida na disciplina de metodologia de ensino de Ciências ofertada pelo curso de licenciatura em Ciências Biológicas da Universidade Federal de Lavras, MG. A aula buscou construir conceitos referentes aos movimentos internos da Terra utilizando como estratégia metodológica uma peça teatral, baseada na mitologia da cultura chilena do povo Mapuche. Através desta ferramenta pedagógica foi possível compreender suas relações com o processo de ensino aprendizagem de ciências e trabalhar com a diversidade cultural. A aula foi aplicada aos licenciandos que cursavam a disciplina e, a partir da análise feita por eles, percebe-se que o uso da dramatização permitiu abordar o tema de uma forma mais dinâmica e assim construir os conceitos propostos de maneira mais interativa e coletiva.

PALAVRAS-CHAVE: Formação de professores; Ensino de Ciências; Mitologia e Educação.

\section{ABSTRACT}

The objective of this work is to report and analyze a class developed in the discipline of teaching methodology offered by the undergraduate course in Biological Sciences of the Federal University of Lavras, MG. The class tried to construct concepts referring to the internal movements of the Earth using as methodological strategy a theatrical play, based on the mythology of the Chilean culture of the Mapuche people. Through this pedagogical tool it was possible to understand their relationships with the teaching process learning science and work with cultural diversity. The lesson was applied to the licenciandos that studied the discipline and, from the analysis made by them, it is noticed that the use of the dramatization allowed to approach the theme in a more dynamic way and thus to construct the proposed concepts in a more interactive and collective way.

KEY WORDS: Teacher training; Science teaching; Mythology and Education.

\section{RESUMEN}

Se pretende con este trabajo relatar y analizar una clase desarrollada en la disciplina de metodología de enseñanza de Ciencias ofrecida por el curso de licenciatura en Ciencias Biológicas de la Universidad Federal de Lavras, MG. La clase buscó construir conceptos referentes a los movimientos internos de la Tierra utilizando como estrategia metodológica una pieza teatral, basada en la mitología de la cultura chilena del pueblo Mapuche. A través de esta herramienta pedagógica fue posible comprender sus relaciones con el proceso de enseñanza, aprendizaje de ciencias y trabajar con la diversidad cultural. La clase fue aplicada a los licenciados que cursaban la disciplina y, a partir del análisis hecho por ellos, se percibe que el uso de la dramatización permitió abordar el tema de una forma más dinámica y así construir los conceptos propuestos de manera más interactiva y colectiva.

PALABRAS CLAVE: Formación de profesores; Enseñanza de Ciencias; Mitología y Educación. 


\section{INTRODUÇÃO}

O pensamento fragmentador e determinista sobre o ensino de Ciências é percebido nos currículos predominantemente prescritivos e conteudistas, contribuindo para que o ensino no cotidiano escolar seja, em sua maioria, expositivo e memorístico (Levy e Santos, 2004, p.100). Estudar, pensar e criar formas de se contrapor a esse perfil de educação é responsabilidade também das universidades brasileiras, por isso a existência de disciplinas que discutam e proponham outras formas de se entender a educação torna-se fundamental no currículo das licenciaturas.

Neste sentido, as demandas da sociedade contemporânea requerem que a escola repense as estratégias metodológicas, propondo práticas pedagógicas com o intuito de fomentar a formação de estudantes capazes de serem protagonistas de sua aprendizagem (Lima e Borges, 2007 , p. 9). Deste modo, elaborar aulas utilizando os diversos recursos pedagógicos existentes de forma crítica possibilita a ampliação do leque formativo dos estudantes e insere aspectos culturais dentro dos conteúdos programáticos.

Para proporcionar um ensino deste modo, é fundamental que os futuros professores tenham uma formação neste sentido, ou seja, um ensino contextualizado que possibilite que os conhecimentos conceituais e pedagógicos estejam em consonância. No entanto, como aponta Libâneo (2015), o que se tem observado é que a organização do currículo dos cursos de formação inicial de professores tem se estruturado de modo a formar o professor especialista, apresentando forte dicotomização entre saberes específicos e saberes pedagógicos. Com isso, o docente não conseguirá atuar como mediador entre o conhecimento e o aluno e, dessa maneira, o aluno pode apresentar dificuldades em se apropriar do que é ensinado e, consequentemente, em entender o mundo que o cerca.

Pensando nisso, a proposta da disciplina de Metodologia do Ensino de Ciências do curso de licenciatura em Ciências Biológicas da Universidade Federal de Lavras-MG aos discentes é a construção de metodologias de ensino que possibilite um exercício teórico-prático referente ao planejamento e desenvolvimento de aulas de ciências.

Dessa forma, apresentaremos neste trabalho uma experiência realizada no âmbito da disciplina para o ensino de vulcanismos e movimentos internos da terra. Como se sabe, a escala de tempo e espaço das Placas Tectônicas é muito maior do que nossos sentidos podem captar (FURLAN et al., 2018). E, como ressalta Paschoale (1984), um dos fatores que dificulta o processo de construção dos conhecimentos geológicos trata-se da incompatibilidade de escala entre nosso aparato perceptivo-interpretador e a escala espaço-temporal do fenômeno estudado.

Como estratégia pedagógica para o ensino dos movimentos internos da terra e vulcanismo, utilizamos a mitologia dos povos Mapuche apresentada por meio de um teatro. Os Mapuche são um povo indígena da região Centro sul do Chile e do sudoeste da Argentina, também conhecidos como araucanos. Por conta do processo de despojo territorial, mais que a metade da população indígena Mapuche vive hoje em dia em zonas urbanas, muitas mantendo, entretanto, vínculos com suas comunidades de origem. De maneira geral o movimento Mapuche luta pela recuperação de seu território ancestral, por mudanças constitucionais em prol dos direitos indígenas e reconhecimento por parte dos Estados de suas especificidades culturais. 
Em consonância com Ferreira e Nascimento Junior (2014) os mitos trazem elementos que nos permitem compreender parte da história e da existência da humanidade caracterizando como recursos pedagógicos eficientes. Além disso, a estrutura mitológica tem uma grande importância antropológica, já que demonstra a cultura e o pensamento de um povo.

Diante dessas considerações, o presente trabalho tem como objetivo, além de apresentar a experiência desenvolvida no âmbito da disciplina, discutir seus resultados a fim de entender como tal atividade auxiliou na construção de conhecimentos referentes aso movimentos internos da Terra e como a própria disciplina contribui para a formação inicial de professores de ciências.

\section{DESENVOLVIMENTO}

\section{A proposta da aula}

Esse projeto de aula foi construído durante a disciplina de Metodologia do Ensino de Ciências, ofertado para alunos do terceiro período do curso de licenciatura em Ciências Biológicas da Universidade Federal de Lavras (UFLA), MG. Na ministração, tínhamos o objetivo de manter uma maior interatividade com os estudantes e desenvolvendo estratégias metodológicas que possam romper com o ensino tradicional realizado de forma expositiva. $\mathrm{O}$ tempo proposto para a aula era 30 minutos.

A proposta de aula foi baseada em um dos eixos temáticos dos Parâmetros Curriculares Nacionais (BRASIL, 1998), Terra e Universo. O plano de aula se constitui a partir da temática 'Movimentos Internos da Terra: placas tectônicas' e tinha como objetivo o ensinar, para os alunos do terceiro ciclo ( $6^{\circ}$ e $7^{\circ}$ ano), a teoria da tectônica de placas usando o vulcão como modelo. Como habilidade proposta para a aula eles também deveriam compreender os outros fenômenos internos (terremotos, tsunami, maremotos) com relação ao que foi apresentado na aula a respeito dos vulcões. Outro requisito da disciplina é a inserção dos Temas Transversais, propostos pelos PCN, na aula a ser desenvolvida. Neste caso, o tema transversal a ser trabalhado nesta aula foi Pluralidade Cultural.

Após a definição do tema da aula e a estratégia pedagógica serem escolhidos, o projeto de aula foi apresentado aos bolsistas do Programa Institucional de Bolsas de Iniciação à Docência (PIBID) de Biologia da UFLA. A contribuição dos pibidianos vai no sentido de levantar os pontos fortes da aula e os pontos a serem melhorados, orientando para uma melhor dinâmica e potencialização da aula.

\section{A descrição da aula}

A aula foi ministrada aos licenciandos que estavam matriculados na disciplina, teve duração de 30 minutos e foi dividida em três momentos. No primeiro, foi encenado o mito do Cherufe (história de nossa autoria) que fazia um paralelo com o conhecimento científico a ser trabalhado na aula.

\section{Descrição da peça Teatral: Mitologia Chilena- Vulcanismo}

Narrador: Os antigos mapuches contavam histórias de uma famosa criatura humanoide que se alimentava de pessoas e causava grande espanto e aterrorizava a região chilena.

Cherufe : Eu sou forte, invencível, feito de magma e pedras. Eu moro nas piscinas de magma 
no fundo dos vulcões chilenos e me alimento de pessoas! Quando estou com fome eu fico muito bravo!

Narrador: Cherufe era uma criatura devastadora e ninguém conseguia detê-lo. Até que um dia a mandato do deus Sol, vendo o tamanho caos que Cherufe estava causando enviou uma de suas filhas para colocar um fim em suas façanhas.

Deusa: Chega Cherufe! A mandato de meu pai, o deus Sol, fui enviada para acabar com toda a tragédia que você tem causado!

Cherufe :Não! Você nunca vai me vencer! Vou destruir toda essa aldeia! (risadas maléficas)

Deusa: Você mal sabe o que te espera! (pegar a espada)

Chefure tira a tiara/o fogo apaga) Você vai ficar congelado para sempre!
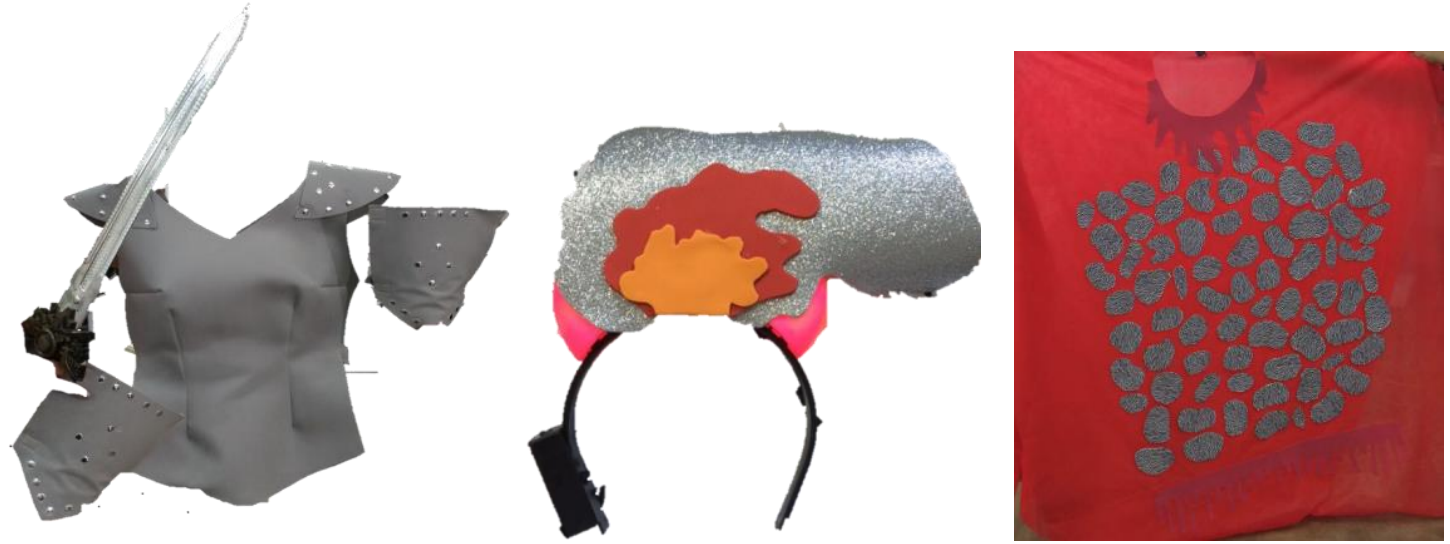

Figuras 1, 2 e 3: Vestimenta utilizada no teatro.

Fonte: Arquivo pessoal da pesquisadora
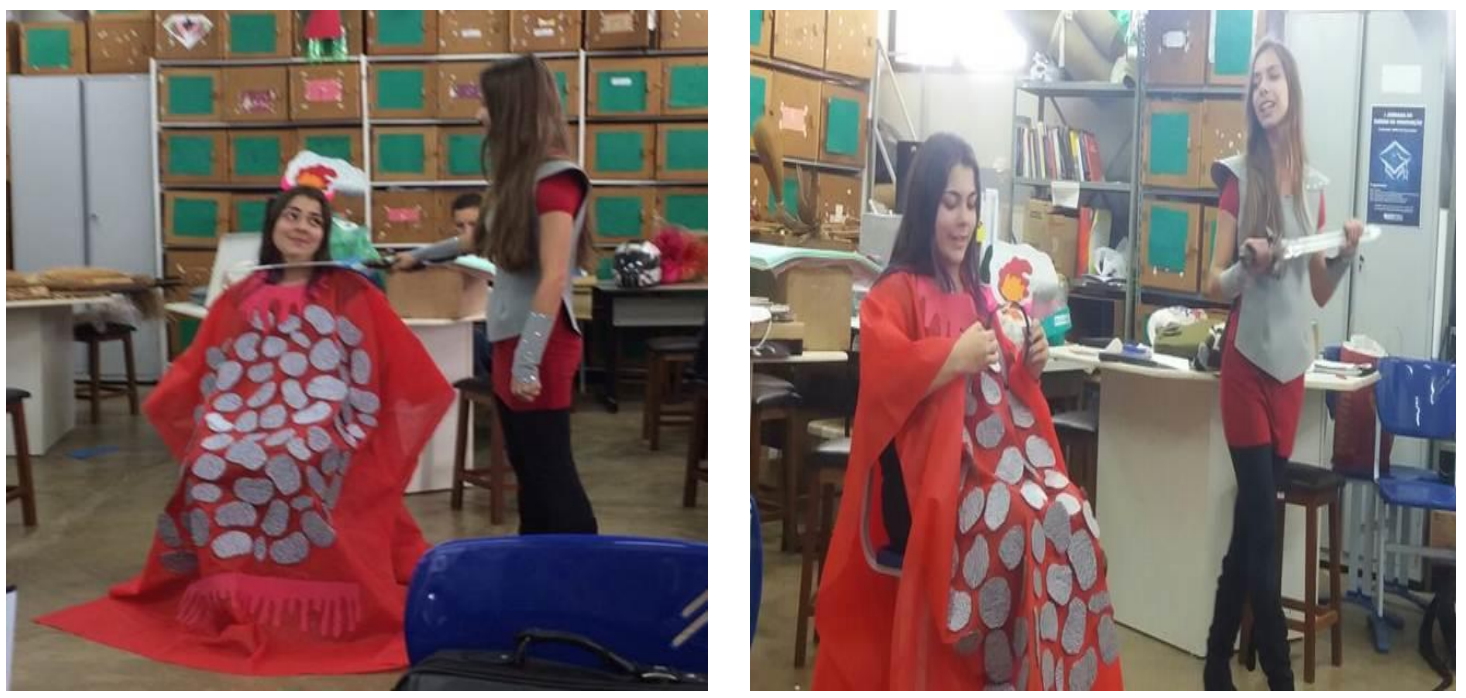

Figuras 4 e 5: Apresentação da narrativa

Fonte: Arquivo pessoal da pesquisadora

No segundo momento, foram levantadas algumas questões problematizadoras, como, por exemplo: $O$ que é vulcão? $O$ que sai do vulcão? Por que não existem vulcões no Brasil? $A$ 
medida que os alunos respondiam as perguntas eram feitas mediações que auxiliavam na construção dos conceitos de forma coletiva.
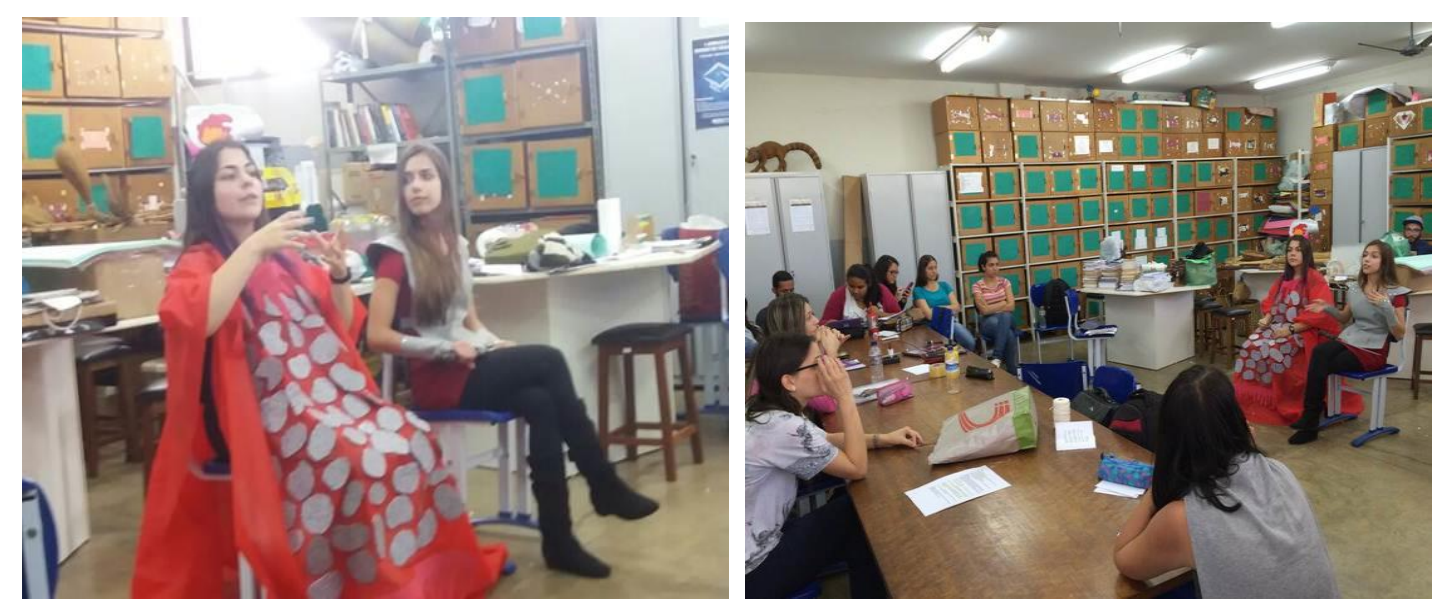

Figuras 6 e 7: Explicação dos fenômenos internos da Terra e a construção do conhecimento com os alunos. Fonte: Arquivo pessoal da pesquisadora

No terceiro momento, foi proposto que os alunos desenvolvessem uma narrativa que retratasse os outros movimentos internos da Terra, com o intuito de desenvolver o conhecimento científico assim como trabalhar com sua criatividade.

\section{Narrativas desenvolvidas pelos estudantes Grupo 1}

O Peixe Dourado

"Há muitos anos atrás, em uma ilha, morava uma tribo indígena. Um certo dia, alguns pescadores deste grupo, saíram para pescar. Logo que chegaram ao mar, avistaram um belo peixe dourado e diferente. Se sentiram encantados com o animal e o desejaram, pois pensaram que seria uma deliciosa refeição para a tribo. Depois de várias tentativas conseguiram pegá-lo, mal sabiam eles que ao fazerem isso seria o fim da paz na tribo.

O Deus do mar se revoltaram com os indígenas por ter pescado seu animal sagrado, e revoltou se vingar deles causando um tremor terrível no mar e matando todos os curumins.

Assim, surgiu a lenda do maremoto. E segundo os indígenas, toda vez que o Deus mar se lembra da perda do seu peixe dourado, ele se revolta e causa um tremor no mar".

\section{Grupo 2}

\section{O Terremoto}

"Era uma vez um caso de amor entre uma deusa e um mortal. Como castigo, os deuses condenaram seu amor e um fruto amaldiçoado nasceu. Gaya, deusa da terra, deu a luz a um gigante que aterrorizava a população causando terríveis tremores ao pisar no chão.

Suas pegadas originavam enormes montanhas e ele sempre devastava as plantações.

Homens guerreiros se reuniram e quiseram por um fim a situação e interraram vivo. Até hoje, ao tentar escapar, sente-se o tremor da terra a longas distâncias". 
Grupo 3

\section{O Mito da Democracia}

"Em uma era de devastação, Temer o rei da sujeira, reinava sob a Terra. Trazia fogo e destruia a vida dos litorâneos; trazia a tristeza, a morte e tudo de ruim que existia.

Vendo a ruína que se transformara a Terra por causa de Temer, Democracia, a entidade suprema do mar; resolveu intervir. Chamou todos os tipos de vida existente no mar para juntar forças para derrotar Temer e deixar a vida na Terra em paz. Eles deram as mãos e conseguiram juntos fazer uma onda gigante que limparia a Terra da sujeira que Temer espalhou e jogaria tudo no fundo dos mares, para que lá ele nunca mais saísse."

Ao final da aula foi pedido que os licenciandos avaliassem, por escrito, a prática desenvolvida. A partir das falas dos estudantes, e das atitudes observadas durante o desenvolvimento da aula, esta prática foi analisada.

\section{RESULTADOS E DISCUSSÃO}

Após o desenvolvimento da aula, os licenciandos participantes fizeram colaborações referentes aos pontos fortes e pontos a serem melhorados na aula. As falas encontram-se descritas abaixo:

P1: "O teatro é uma ideia bem dinâmica e interativa, tornando a aula criativa. Foi divertida e abordou bem o assunto. Como pontos a melhorar, acho que poderiam ter deixado os alunos falarem mais os conteúdos ao invés de o chegarem apresentando".

P2: "Pontos fortes: ótima contextualização, interdisciplinidade. Pontos fracos: não consigo ver nenhum".

P3: "Pontos fortes: muito divertida, dinâmica, com um teatro sobre um conto mitológico sobre o vulcanismo. Ficou bem claro o assunto tratado. Pontos fracos: eu não vi pontos fracos".

P4: "Achei a apresentação muito boa e interativa, porém relativamente pequena, poderia ter durado mais tempo, mas o restante foi bem interativo com os alunos, e achei muito boa também a atividade de fixação".

P5: "Pontos positivos: boa forma de avaliação. Boa exploração dos conceitos. Divertido apresentação teatral. Pontos que podem melhorar: as vezes a aula ficou um pouco expositiva". P6: "Pontos fortes do trabalho: gostei muito da aula, a encenação foi muito boa e deixou a aula bem descontraída. Vocês dominaram bem o tema. Pontos a melhorar: não enxerguei pontos a serem melhorados".

P7: "Pontos fortes gostei da ideia do teatro para expor uma lenda que se encaixou no tema.

Pontos fracos: poderia ter tido uma discussão que se interagisse mais com os ouvintes".

P8: "Pontos fortes: uso da mitologia, que explica os eventos que ocorrem na natureza de forma fantasiosa, e a explicação científica deles. Podem melhorar: poderiam ter usado mais o mito e questões para construir os conceitos, e não somente a explicação do científico".

P9: "Pontos fortes: Teatro excelente, contextualização, temas transversais, interdisciplinaridade. Pontos fracos: o teatro poderia ser maior ( $\mathrm{rs}$ )".

P10: "Pontos positivos: muito criativo foi claro o teatro e a explicação. Aula dinâmica e divertida, clara e objetiva".

P11: "Pontos positivos: Foi muito bom e criativo. O que pode melhorar: podia abrir mais para 
discussão".

P12: "Pontos fortes: a peça, o tema, o dinâmica do grupo, a dinâmica em relação aos alunos.

Pontos fracos: a peça foi muito curta".

P13: "Pontos positivos: criatividade na apresentação do teatro, aula dinâmica, fantasias interessantes, bem claro o conteúdo. Pontos a melhorar: não vi pontos fracos".

P14: "Pontos positivos: interação, teatro, o figurino. Pontos negativos: pouco tempo para discussão".

\section{Um pouco de discussão}

Tendo como base as avaliações dos alunos, foi possível levantar algumas questões. Uma delas é a questão da utilização do teatro como ferramenta pedagógica como mencionado pelos participantes P1; P3; P6; P7; P9; P10; P13; P14. Em consonância com Torres e Sales (2000) as atividades lúdicas na biologia proporcionam uma aprendizagem descontraída e, ao mesmo tempo, proveitosa. Para estes autores, o teatro pode ser um meio pelo qual os educandos refletem sobre muitos temas referentes á ciências. Neste mesmo sentido, Peraçoli et al. (2007) indicam que um aspecto importante dos teatros é que alguns determinados conceitos de biologia podem sair do papel e se transformar em algo concreto, visível e que pode ser manipulado, assim sendo uma ferramenta de destaque para o ensino.

Outros aspectos relevantes ressaltados foram a questão da interação, da criatividade, da dinamicidade e contextualização que a aula proporcionou como destacados pelos participantes P2; P3; P4; P9; P12; P13; P14. Esses aspectos são fundamentais para a construção do aprendizado de maneira efetiva. Tais características devem ser priorizadas no ambiente de ensino-aprendizagem, uma vez que o processo de aprendizagem é bastante complexo, estas características podem contribuir para uma maior interação, motivação e interesse por parte dos estudantes. Segundo Gil (2009), na perspectiva contemporânea, o professor deixou de ser o principal responsável pelos resultados obtidos e os alunos deixaram de ser encarados como seres passivos e imaturos. O foco principal está na aprendizagem, o papel do professor é ajudar a aprender. Neste sentido, a interação, a criatividade, a dinamicidade e a contextualização são questões fundamentais de serem levadas em conta na busca por uma aprendizagem mais significativa, possibilitando um envolvimento maior do educando.

Já o participante P8 trás a utilização da mitologia como sendo um ponto forte da aula. No entanto, ele ressalta que poderia ter explorado um pouco mais do mito na construção de conceitos. De acordo com Silva et al. (2017), a utilização dos mitos em sala de aula permite aos professores trabalharem a questão do multiculturalismo, buscando entender com os alunos as diversas culturas existentes a fim de entender como essas culturas influenciaram a sociedade como vemos hoje e, também, busca superar o preconceito cultural, ainda bastante presente na nossa sociedade. Leal e Gouvêa (2000) dizem que 'o mito é transmitido sob o olhar das culturas, das religiões, do imaginário, das relações de poder, do gênero etc'. Desse modo, como as relações sociais influenciam a maneira como o mundo era visto deve ser discutida, podendo ainda, comparar como essas relações interferem no modo que entendemos o mundo atualmente. Neste sentido, a questão do mito pode ser bastante explorada pelos professores 
durante o processo de ensino-aprendizagem.

Com base nas falas dos participantes e nas vivências proporcionadas aos estudantes, pode-se afirmar que a disciplina de Metodologia de Ensino de Ciências têm se destacado no sentido de promover uma relação entre os conhecimentos científicos e pedagógicos sendo esta relação fundamental para uma práxis efetiva quando estes estudantes estiverem na escola. Segundo Fagundes et al. (2012), o ensino de ciências tem como foco a formação de alunos críticos, conscientes e embasados para melhor compreender o comportamento da sociedade atual. Neste contexto é exigido do docente um amplo conhecimento, tanto em relação aos conteúdos específicos quanto à utilização de materiais didáticos e pedagógicos. Desse modo, a utilização de ferramentas pedagógicas diferenciadas tem se mostrado uma grande aliada no processo de ensino-aprendizagem, sendo fundamental que tais práticas estejam inseridas na formação de professores.

Nas últimas décadas, o debate em torno do processo de ensino e aprendizagem em ciências, ganhou muita força o uso de metodologias alternativas no ambiente educacional. Sendo um tema discutido e debatido por diversos autores e pesquisadores da área. Além disso, na literatura encontramos interessantes sugestões de estratégias de ensino não tradicionais.

No entanto, apesar da eficácia das metodologias alternativas, é perceptível a relutância dos educadores em trazê-las para as salas de aula que, mesmo "[..] motivados, são inseguros diante das novas ações" (PACHECO; PACHECO, 2013, p.44). Na perspectiva dos educadores, o uso de metodologias alternativas de ensino caracteriza o movimento de uma zona de conforto para uma zona de risco, segundo a terminologia de Penteado (2004). Assim, muitos preferem continuar na forma de ensino tradicional por comodismo, medo, insegurança e falta de preparo.

\section{CONSIDERAÇÕES FINAIS}

A disciplina de Metodologia de Ensino de Ciências se mostrou um importante espaço de formação docente, uma vez que possibilita uma aproximação dos estudantes com a práxis pedagógica, mobilizando e articulando os conhecimentos científicos e os saberes pedagógicos e minimizando a dissociação entre esses elementos que são fundamentais para a profissão docente.

A partir da análise e discussão do presente trabalho, pode-se considerar que a utilização do teatro e da mitologia Mapuche se mostraram estratégias pedagógicas interessantes para o ensino de conceitos referentes os movimentos internos da Terra bem como relações com as questões culturais de grande importância no processo de ensino-aprendizagem. Em consonância com Andrade e Nascimento Júnior (2014), novas práticas de ensino são muito importantes para mudar o cenário da educação atual, e que práticas formativas contribuem significativamente para que haja tal mudança.

Por fim, é relevante destacar a importância dos bolsistas do Programa Institucional de Bolsas de Iniciação à Docência (PIBID) de Biologia da UFLA na construção da aula apresentada. Esse diálogo entre o PIBID e a disciplina tem se mostrado eficiente no processo de formação de professores. 


\section{REFERÊNCIAS BIBLIOGRÁFICAS}

ANDRADE, Mariana Nayara Bonilha; NASCIMENTO JÚNIOR, A. F. Uma parceria entre museu, PIBID e escolas na formação inicial de professores de ciências e biologia da Universidade Federal de Lavras MG. Revista da Associação Brasileira de Ensino de Biologia (SBEnBio), v. 7, p. 5618-5629, 2014.

BRASIL. Secretaria de Educação Fundamental. Parâmetros curriculares nacionais: ciências / Secretaria de Educação Fundamental. -Brasília : MEC/SEF, 1998.

FAGUNDES, Wagner André; SALOMÓN Gabriela Ronchi; PEREIRA, Cristiano Marcondes; CRISOSTIMO, Ana Lúcia. Metodologia de ensino de biologia relacionada à temática biotecnologia. III Simpósio Nacional de Ensino de Ciências e Tecnologia. Ponta Grossa, de 26 a 28 de setembro, 2012.

FERREIRA, Wellington Donizet; NASCIMENTO JUNIOR, Antonio Fernandes. A mitologia grega como estratégia para o ensino de zoologia: articulando a biologia com a língua portuguesa e suas literaturas. In: XXIII Congresso de Pós-Graduação da UFLA, 2014, Lavras. Anais do XXIII Congresso de Pós-Graduação da UFLA, 2014.

FURLAN, Thays Zigante; SANTIL, Fernando Luiz de Paula 2; GASPARETTO, Nelson Vicente Lovatto. Análise semiótica dos mapas no ensino das Placas Tectônicas. Revista Espacios. V.39. N.10. p.33. 2018.

GIL, Antônio Carlos. Metodologia do Ensino Superior. 4. ed. São Paulo: Atlas, 2009.

LEAL, Maria Cristina; GOUVÊA, Guaracira. Narrativa, mito, ciência e tecnologia: o ensino de Ciências na Escola e no Museu. Ensaio - Pesquisa em Educação em Ciências. Vol. 92. № 1. 2002.

LEVY, Lênio Fernandes.; SANTO, Adilson Oliveira Espírito. O ensino e a aprendizagem de ciências e matemáticas, a transversalidade, a interdisciplinaridade e a contextualização. Amazônia (UFPA.2004), v.1, p.99-103, 2004.

LIBÂNEO, José Carlos. Formação de Professores e Didática para Desenvolvimento Humano. Educação \& Realidade, Porto Alegre, v. 40, n. 2, p. 629-650, abr./jun. 2015.

LIMA, Valderez Marina Rosário.; BORGES, Regina Maria Rabello. Conteúdos e estratégias de ensino utilizadas em aulas de Biologia. In: VI Encontro Nacional de Pesquisa em Educação em Ciências, 2009, Florianópolis.

PACHECO, José; PACHECO, Maria de Fátima. A Escola da Ponte sob múltiplos olhares: palavras 
de educadores, alunos e pais. Porto Alegre: Penso, 2013.

PASCHOALE, C. Geologia como Semiótica da Natureza. PUC, São Paulo. 1984.

PENTEADO, Miriam Godoy. Redes de trabalho: expansão das possibilidades da informática na educação matemática da escola básica. In: BICUDO, Maria Aparecida V; BORBA, Marcelo de Carvalho. (Orgs.). Educação Matemática em movimento. São Paulo: Cortez, 2004. p. 283-295.

PERACOLI, Ana Paula; NEIVERTH, Adeline; NASCIMENTO JÚNIOR, Antonio Fernandes . Produção de um teatro de máscaras de dinossauros sul americanos para sua divulgação, ensino de paleontologia e educação ambiental. In: X Encontro Paranaense de Educação Ambiental, 2007, Maringá. Anais do X Encontro Paranaense de Educação Ambiental, 2007. p. $1-11$.

SILVA, André Maciel da; SILVA, Gabriel Gonçalves Ribeiro; NASCIMENTO JÚNIOR, Antonio Fernandes. O uso do role-playing gamepara o ensino de biologia: aprendendo zoologia de maneira não convencional. Periódico Eletrônico do Fóruma Ambiental da Alta Paulista. V. n. 2 P.1-10. 2017.

TORRES, E. C.; SALES, V. R. Educação Ambiental e o teatro de fantoches. In: HAMBURGER, E. W.; MATOS, C. (orgs). O desafio de ensinar ciências no século XXI. São Paulo: Universidade de São Paulo- Estação Ciências; Brasília: CNPq, 2000. p. 112-115. ODUM, E. P. Ecologia. Rio de Janeiro: Guanabara, 1988. 